\title{
The State of Indifference and Its Relationship to The Achievement of The Event of 100 M Butterfly Swimming for The Youth Category
}

\author{
Othman Mahjoub Khalaf, Prof.Dr. Mustafa Salah EIDin Aziz \\ University of Baghdad / College of Physical Education and Sports Sciences
}

DOI: $10.37648 /$ ijrssh.v10i04.030

Received:19 ${ }^{\text {th }}$ July, 2020; Accepted: $17^{\text {th }}$ August, 2020; Published: 14th December, 2020

\begin{abstract}
The aim of the research is to identify the relationship between the state of indifference and the achievement of swimming 100 $m$ butterfly for the youth category by measuring indifference as a psychological variable and its relationship to achievement as a physical variable. The researcher used the descriptive approach in order to suit the nature of the problem. Al-Kadhimiya and Adhamiya Swimming Clubs The researcher used the indifference scale through a special form for that. The form was submitted to the research sample before the race for 120 minutes, noting that the exploratory experiment was conducted on the Adhamiya club, which numbered (3) swimmers outside the main sample sample, and after the statistical treatments, it was revealed Results: There is a high correlation between the state of indifference and the achievement of swimming $100 \mathrm{~m}$ butterfly for the youth group, and on the basis of that, the two researchers recommended the importance of addressing the state of indifference due to its great importance on the results of the race, and conducting similar studies in other activities that require speed in achievement
\end{abstract}

Key Words: (The state of indifference, Swimming $100 \mathrm{~m}$ butterfly)

\section{INTRODUCTION}

Many swimmers suffer from psychological disorders before the race, and there are not a few who do not care about the psychological side, whether it has a negative effect such as anxiety, fear and other manifestations, or the positive side such as confidence, motivation or willingness to struggle, as explained by sports psychologists, as (Allawi 1975) He showed that the athlete goes through one of the conditions before the race, which is the start fever, indifference, and readiness to struggle, and the apathy state whose owner experiences psychological and physiological symptoms, including a decrease in the degree of arousal and disturbance to the point of lethargy, a negative emotional state accompanied by boredom and dissatisfaction. As well as starting the race in a manner predominantly slack, lazy and lethargic.

Ramzy, 2009) explained that this emotional state before the competition that may lead to an increase in the level of performance or otherwise, and the matter depends on the test score of the player in the pre-competition period as indicated (Sukkar, 2002) that whatever the degree of the pre-psychological preparation of the trainee, from It is necessary to take measures to stimulate the appropriate mood in him. Therefore, the coach should raise the player to a positive situation. Allawi (1998) and (Al-Adawi, 1977) agreed that the state of indifference has a negative effect on the player before the race, which makes the swimmer not pay attention to the level of the opposing player or the importance of the tournament. 
The state of indifference is a negative condition for athletes, as it is attributed to the increase in the cessation processes in the brain and the marked decrease in the processes of nervous excitation (Damd 2010)

And (Al-Jubouri 2016) stated that the coach should find motivational means to get the swimmer out of a state of indifference to a state of readiness and confidence. Which made the two researchers to find a tool to measure the state of indifference and its relationship to the achievement of the effectiveness of $100 \mathrm{~m}$ butterfly swimming for the youth group.

\section{MATERIALS AND METHODS:}

Stability:

To verify the reliability of the indifference scale, the researchers used: procedures and tools

The two researchers used the descriptive approach to suit the nature of the research problem, the research community: the Kadhimiya and Adhamiya clubs swimmers, the youth group at the Adhamiya club pool The research community represents the $100 \mathrm{~m}$ distance swimmers from the youth group of the Kadhimiya and Adhamiya clubs, who are (17) swimmers, where the research sample included (16) swimmers, and so it included The percentage of the sample in the community is $97 \%$. The sample of the pilot experiment consisted of (3) individuals, at a rate of $20 \%$. The two researchers distributed the form to the swimmers before conducting the actual test before (120) minutes to race a distance of $100 \mathrm{~m}$ butterfly with the help of the work team. Then it was handed over to the researchers for the purpose of unpacking the data and conducting a $100 \mathrm{~m}$ butterfly swimming test and documenting Fulfill every swimmer on the form.

It was agreed between the researchers and the supervisor to suggest a measure of indifference status. The two researchers drafted the paragraphs of the scale in its initial form, which amounted to 15 paragraphs and were presented to experts and specialists.

The apparent validity was verified and it is one of the most important types of truthfulness in psychological measurements and indicates the relevance of the paragraph to be measured, by presenting the scale in the initial form (14) an expert to judge the validity of the paragraphs. (8) experts approved and rejected (6) experts. The two researchers extracted the discriminative power by using (t.test) to denote the differences of the arithmetic means of two independent samples between the upper and lower group. The researchers adopted the paragraphs in which the significance value is less than the approved level of significance (0.05) and the degree of freedom (48) and (8) paragraphs were canceled and the preservation of (7) Paragraphs

Internal consistency coefficient

The researchers used a kind of internal consistency to achieve this:

.1The relationship of the paragraph score to the total score of the scale: It is to find a correlation relationship between each paragraph and the total score of the scale for the individuals of the sample for the purpose of correlating the score of the paragraph with the total degree of the scale. Therefore, the paragraph represents the characteristic to be measured is one of the necessary indicators that show the extent of the scale's validity in measuring the characteristics to be measured Through the paragraphs that grow the scale.

Internal consistency

The two researchers used the scale as a whole using the Pearson correlation coefficient between the paragraph score and the total score of the scale. The two researchers also extracted the correlation relationship between the paragraph score and the total score of the scale. It was found that the paragraph $(1,4,5,7,9,13,14,15)$ is not significant At the level of significance (0.05), it was deleted so that the scale paragraphs would be (7) paragraphs.

To verify the stability of the indifference scale, the researchers used:

Hashing method -

Halftone -

- Fakronbach's method, as shown in Table (1) which indicates the coefficients of the indifference scale 
Table (1)

It shows the stability coefficients for the indifference scale

\begin{tabular}{|l|l|l|l|l|}
\hline \multirow{2}{*}{ Alpha Cronbach } & \multicolumn{2}{|l|}{ Halftone hash } & the scale & sequence \\
\cline { 2 - 5 } & $\begin{array}{l}\text { Stability } \\
\text { coefficient }\end{array}$ & Firmness of half the test & \\
\hline 0.813 & 0.820 & 0.621 & Scale & 1 \\
\hline
\end{tabular}

Exploratory experience:

The exploratory experiment was conducted on a group of (3) young swimmers affiliated with Baghdad clubs who were randomly assigned outside the application sample for the purpose of extracting the scientific basis transactions with the help of the assistant work team. ( 8 to 10 minutes, and thus the scale is fully ready for application for the purpose of statistical analysis of the paragraphs.

Swimming scale $100 \mathrm{~m}$ butterfly finished:

All the paragraphs of the 100-meter butterfly swimming scale are statistically significant except for (8) paragraphs, as they are not significant at the level of significance (0.05), so it was rejected as the number of paragraphs (7) and here the goal was achieved, which is to prepare the indifference scale for young swimmers for the Kadhimiya and Adhamiya clubs depending on the statistical treatments that Done to achieve the scientific conditions of the paragraphs

The two researchers distributed the scale forms (the questionnaire to the application sample consisting of (16) individuals who were deliberately selected from the parent community of (17) individuals. From the sample after answering it for the purpose of unpacking responses and for applying statistical methods

:Statistical means

The researchers used the spss statistical bag as it contains all the treatments of the research study.

(Arithmetic mean deviation, standard, Pearson simple correlation coefficient, Alpha-Crowe-Nabach equation)

And $(t)$ test for independent samples

\section{RESULT AND DISCUSSION:}

The table shows the mean, standard deviation, correlation coefficient, and the significance level of the tests under investigation

\begin{tabular}{|l|l|l|l|l|l|l|}
\hline indication & $\begin{array}{l}\text { Significance } \\
\text { level Siq }\end{array}$ & $\begin{array}{l}\text { Degree of } \\
\text { freedom }\end{array}$ & $\begin{array}{l}\text { Correlation } \\
\text { coefficient }\end{array}$ & $\begin{array}{l}\text { standard } \\
\text { deviation }\end{array}$ & $\begin{array}{l}\text { Arithmetic } \\
\text { mean }\end{array}$ & $\begin{array}{l}\text { Swimming } 100 \\
\text { butterfly } \\
\text { Indifference } \\
\text { condition }\end{array}$ \\
\hline moral & 0.000 & 9 & $* * 0.841$ & 13.33 & 40.29 & $\begin{array}{l}\text { State of } \\
\text { indifference } \\
\text { (degree) }\end{array}$ \\
\cline { 4 - 6 } & & & & 2.321 & 25.18 & $\begin{array}{l}\text { Swimming 100m } \\
\text { butterfly }\end{array}$ \\
\hline
\end{tabular}

$\mathrm{N}=10$

The value is significant at 0.05 reliability

The above table shows the correlation coefficient between the $100-\mathrm{m}$ butterfly swim test and the indifference scale. There is a positive significant correlation between achievement and swimming $100 \mathrm{~m}$ butterfly. Its value reached 0.841 and this value is significant at the level of 0.05 , which indicates that there is a strong correlation between the achievement of $100 \mathrm{~m}$ swimming and the state of indifference, and this means that by observing the value of the standard deviation of the $100 \mathrm{~m}$ butterfly swimming variable (2.321), which is a high value indicating the great variation between swimmers from As this variable had 
a relationship with the deviation of the achievement variable as well, as some swimmers had indifference indicators, while other swimmers had low indices, which had an effect on the standard deviation of their achievement, and thus the results showed that there is a strong correlation between The variable of indifference status and achievement in a 100-m butterfly swimming. This study came similar to Al-Nadawi's study (2005) that swimmers suffer from psychological disorders, and it also concurs with the study of McKay (2000), where he indicated that those with a low level in some negative psychological variables have achieved a mathematical achievement higher than Those with a high level of negative psychological variables in the level of achievement.

Through the researchers' perusal of previous studies that dealt with topics similar to this topic, where the researchers found that this result is in agreement with the study (Abd al-Salam, 2017), which showed that the emotional state of the player before the match, directly affects the movement performance of the player.

\section{CONCLUSIONS:}

The variation in the degree of apathy among the sample swimmers. -

- There was a strong correlation between the variable of indifference and the achievement of swimming $100 \mathrm{~m}$ butterfly.

\section{ENDORSEMENT:}

-- The need to pay attention to the psychological aspect, especially the variable indifference of swimmers, and to try to reduce its negative impact.

- Conducting similar research for medium and long distance activities in swimming.

- Providing some means that contribute to reducing psychological variables, especially indifference.

\section{REFERENCES:}

- Allawi, Muhammad Hassan, 1975, Sports Psychology, Part 1, Dar Al Ma'arif, Egypt, second edition, Cairo, Egypt.

- Muhammad Husayn Abu al-Tayyib, The Impact of Emotional Intelligence on the Psychological Frequency of the Juniors of the Jordanian Swimming Team, Master Thesis, University of Jordan, Amman, Jordan.

. Damad, Abdul Sattar Jabbar 2010, Psychology in Sports -

- Othman Al-Jubouri 2016 (Self-confidence characteristic and its relationship to self-esteem among students of swimming distances of the Faculty of Sports Sciences, Mutah University) Unpublished Master Thesis, Jordan.

- Al-Nadaawi, Ammar Darwish (2005) Psychological anxiety and its relationship to the level of achievement of handball players, "Journal of Physical Education 14 (1) University of Baghdad, Iraq 35-56.

- McNay, Iyad (2000) Levels of Psychological Anxiety Before Sports Competition among Table Tennis Players in Jordan and Their Relation to Achievement "Unpublished Master Thesis, University of Jordan, College of Physical Education, Amman, Jordan.

Allawi (1998) Introduction to Psychology, 1st Edition, The Book Center, Cairo -

- Ahmad Al-Sayed Abd Al-Salam, (Physical Psychosomatics and their Relationship to Sports Achievement among Karate Players) Journal of Physical Education and Sports Research, Benha University, Volume 19 June (2017) Part One.

- Howayda Ismail Ibrahim, psychological tension and its relationship to selfconfidence among the National Team for the Handicapped swimmers.

- Firas Mahmoud Ammi Al-Khokhi, Building the Frustration Scale for Advance Players in Mosul Clubs, Al-Rafidain Journal for Sports Sciences, College of Physical Education, University of Mosul, Iraq. 